\title{
Merger and Acquisition of Business Organization and its Impact on Human Resources
}

\author{
M. BABY SOUNDARYA, S. MOGHANA LAVANYA* and S. HEMALATHA \\ Department of Agricultural and Rural Management, Tamil Nadu Agricultural University, \\ Coimbatore, 641003 Tamil Nadu India.
}

\begin{abstract}
There is an assumption that, when merger and acquisition takes place, two companies join together will have greater value than the companies functioning alone, ie., to create synergy. Merger and acquisition among the companies are gaining its momentum, due to the enhanced competition among the corporates in domestic and the global market. This paper discusses about merger and acquisition and the motives behind it. Some mergers and acquisitions are unsuccessful due to some factors like financial, marketing and operational issues. Human resource problems in the merged companies also resulted in the failure of the mergers and acquisitions. So, this article proposes to discuss about HR issues at each phase of merger and acquisition, strategies to overcome the issues were also discussed.
\end{abstract}

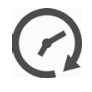

Article History

Received: 24 July 2018

Accepted:05 September 2018

\section{Keywords}

Acquisition;

Human Resource;

Merger.

\section{Introduction}

"Growth is never by mere chance; it is the result of forces working together."

- J James Cash Penney, founder, JC Penney

Globalization has led to the emergence of new business ventures. The existing business organizations have to rejuvenate themselves to face the globalization. The global players are networking with domestic firms to start their innings in India. Mergers and acquisitions of firms seemed to be a best approach to tackle the business competition. Mergers and acquisitions has become an indispensible component of a best business approach of the business world as it plays a key role in reestablishing a business. ${ }^{6}$ In general terms, business combinations are referred as merger and acquisition. Mergers and acquisition has emanated as the innate process of business reorganizing. ${ }^{9}$ There are different motives for companies to enter M\&A namely, shareholder gains, managerial gains, economies of scale, economies of scope, cost savings, taxes exemption, diversification, to raise entry barriers, to obtain multimarket contact and to have better research and development. ${ }^{7}$ The

CONTACT S. Moghana Lavanya $\searrow$ smoghana@gmail.com 9 Department of Agricultural and Rural Management, Tamil Nadu Agricultural University, Coimbatore, 641003 Tamil Nadu India. (c) $($ ) (C) 2018 The Author(s). Published by Enviro Research Publishers. This is an 2 Open Access article licensed under a Creative Commons license: Attribution 4.0 International (CC-BY). Doi: http://dx.doi.org/10.12944/JBSFM.01.01.05 
keen issue in mergers and acquisitions is the status of human resource in the companies that are merged or acquired. The work environment of the companies that are merged or acquired will not be conducive for the employees. This article portrays the impact of mergers and acquisitions on the human resource.

\section{Merger and Acquisition}

Merger is the aggregation of two or more firms which results in continuous function of one firm. ${ }^{8}$ A merger is a unification of two businesses where one exist and the other moves out of business. ${ }^{3}$ The assets and liabilities of the merged company are taken by the acquiring company and it maintains its authenticity after the process of the merger.

An acquisition occurs when one company takes a controlling ownership interest in another firm, a legal subsidiary of another firm, or selected assets of another firm such as a manufacturing facility. ${ }^{6}$ In other words, an acquisition is the purchase of an asset such as a plant, a division, or even an entire company. ${ }^{11}$ Difference between merger and acquisition is given in the Table 1 .

Mergers and acquisitions occur on the basis of lines of business activity, bid of controlling interest ad for strategic transactions. ${ }^{5}$ Many Indian companies have entered into international merger and acquisition in the sectors like pharmaceuticals, $\mathrm{IT}$, telecommunications, steel, construction, etc, which further triggered the acquisition activities in India.

Human resource issues on merger and acquisition Merger and acquisition makes an organization to be unified and larger with different people, processes and technologies. Human Resources (HR) plays a vital role in all stages of $M \& A$. The most sensitive issue in $M \& A$ is the people issues but also the most ignored issue. When a company decides to merge and acquire a company it analyzes their technical and financial feasibility but fails to give importance to the human resources in the firm. Because of this, most of the successful integration has failed to reach success. At times financial and market factors are the reason for the failure of merger and acquisition but the neglect of human resources issues is considered as one the major reason for merger and acquisition failures. ${ }^{13} \mathrm{HR}$ professionals are key in pre-merger discussions and the strategic planning phase of $M \& A$ as it will help them to assess the corporate cultures of the two organizations. ${ }^{1}$ It helps them to identify areas of divergence that hinders the integration process and also with issues related to communication, downsizing, compensation policies, work benefits and company goals to be achieved.

When corporates go for $M$ \& $A, H R$ professionals face lot of issues in three phases like, planning phase, merger phase and post-merger phase. During the planning phase certain HR issues that arises are

Table 1: Differentiation of Merger and Acquisition

\begin{tabular}{|c|c|c|}
\hline Basis & Merger & Acquisition \\
\hline Meaning & $\begin{array}{l}\text { Voluntary fusion of companies } \\
\text { to form a new company }\end{array}$ & $\begin{array}{l}\text { One firm purchases the } \\
\text { business of another firm. }\end{array}$ \\
\hline New company formation & Yes & No \\
\hline Nature of decision & Mutual decision & Friendly and hostile decision \\
\hline Minimum. number of companies & 3 & 2 \\
\hline Purpose & $\begin{array}{l}\text { To increase operational efficiency } \\
\text { and to decrease competition }\end{array}$ & Immediate growth \\
\hline Business Size & More or less same & $\begin{array}{l}\text { bigger than the size of } \\
\text { the acquired company }\end{array}$ \\
\hline Legal formalities & More & Less \\
\hline
\end{tabular}

(Source: Sherman and Hart 2006) 
how to communicate the news to the employees in such a way that they won't be threatened, searching for potential partners and plans to manage the change and create plans to achieve the goal. This issue in the planning phase can be solved through proper planning in terms of leadership, cultural assessment among the corporates, systematic way of implementing merger and acquisitions in such a way that recruitment, selection, performance appraisal, work benefits, work environment and labor relations in the newly merged organization. ${ }^{18}$

The most important HR issues during planning phase are

- To identify the reasons to initiate the activity - to obtain talent is one of the major reason for combinations. Eg. Facebook acquired so many small companies like Faciometrics, Infiniled, etc, to retain talent people. The other reasons might include, technology, research and development. Eg. Bayer Crop Science with Monsanto.

- $\quad$ Appointment of a dedicated senior executive In order to have good leadership, companies might have merged. Eg. Nokia, the global leader in mobile phone business failed in acquisitions due to management vacuum.

- $\quad$ Selection of the wrong partner will diminish the success of integration - So we have to rightfully select the partner. Eg. HP and Compaq was merged in 2001 and after 10 years they proved that the partners were wrong

\section{HR Issues in the Merger Phase}

When merger fails, productivity drops with 50 per cent, leadership attrition soars 47 per cent within 3 years, satisfaction of the employee drops with 14 per cent, employees begin to feel that top management cares more about financials than product quality or people with 80 percent. ${ }^{10}$ At this phase, HR issues like designing of implementation teams, creation of new structure, retaining of key employees, motivating them, change management and communication with the stakeholders are likely to arise.

\section{HR issues in the Post-merger phase}

At this phase HR issues like, cultural differences, which are usually at the heart of the difficulty faced by merging companies, leadership issues, dealing with physiological and psychological effects on individual employees, harmonization of compensation practices, restructuring and optimal staffing, ineffective communication are most likely to arise.Human resource strategies should be identified for a successful merger and acquisitions. They were clear vision, mission and goals, proper business strategy and plan of action, cultural mapping and involving human resource in negotiation cycles, creation of a new organization chart, HR audit with roles, responsibilities and skill sets of the employees, Establishment of common corporate culture would help the employees to work together to achieve the business goals of the new organization, good communication between the different levels of management It would be better to have common culture for the new organization4, engage employees in productive work and keep their motivation / commitment levels at the highest possible levels and eliminate them-us syndrome between the employees by giving them proper training and development and also through individual counseling if required. ${ }^{13}$

\section{Future Prospects}

Most of the studies in mergers and acquisitions are analyzed in financial sector which can be quantified in terms of market shares, net worth, bonds etc. that helps to access whether the merger is successful or not. But it is equally important to analyze whether the merger and acquisition is successful in terms of human resources working in the organization. Analysis can be done by measuring the rate of employee turnover, performance appraisal, job satisfaction, their productivity level and their emotional intelligence level, etc before, during and after merger and acquisition. HR issues at different levels of management can also be assessed so that it would be helpful to give separate kind of training to individual cadres.

\section{Conclusion}

Physical and financial resources alone cannot improve efficiency of an organization by themselves. But human resources are one of the most vital resources for successful merger and acquisition. Success in mergers largely depends on how well the people issues have been addressed, handled and resolved in terms of restructuring, downsizing, harmonization of remuneration practices, psychological and physiological plans. 
So Human resource issues at each stage of merger and acquisition should be assessed and rectified forming new HR strategies and policies. HR policies have a direct impact on the individual employee as it involves their work benefits, attendance, fringe benefits, promotions, transfers, training and insurances. So better HR strategy leads to better success in merger and acquisition.

\section{Acknowledgement}

This research received no specific grant from any funding agency in the public, commercial, or notfor-profit sectors.

\section{Conflict of Interest}

There is no conflict of interest

\section{References}

1. Anderson, J. E. (1999). Making Operational Sense of Mergers and Acquisitions. The Electricity Journal, 12(7), 49-59. doi:10.1016/ s1040-6190(99)00054-8

2. DePamphilis, D. (2003). Acquisitions and Other Restructuring Activities: An Integrated Approach to Process, Tools, Cases, and Solutions. Butterworth-Heinemann.

3. Gaughan (2007). Mergers, Acquisitions, and Corporate Restructurings. John Wiley \& Sons.

4. Hunsaker, P.L., \& Coombs, M. (1988). Mergers and acquisitions: Managing the emotional issues. Personnel Journal, 67, 56-78.

5. Kumar, P.K. (2012). Mergers and Acquisitions (M\&A): The Strategic Concepts for The Nuptials Of Corporate Sector, Innovative Journal of Business and Management, 1(4), $60-68$.

6. Thathaiah, M., \& Nayak, P. (2007). Why do Mergers and Acquisitions quite often fail?, AIMS International, 1(1), 53-69.

7. Motis, J., (2007). Mergers and Acquisitions
Motives, Toulouse School of Economics, University of Crete, 1-31.

8. Piesse, J., Lee, C. L., Lin, L., \& Kuo, H-C. (2014). Merger and Acquisition: Definitions, Motives, and Market Responses, Encyclopedia of Finance, 411-420.

9. Prasad, S. (2007). Cross-Border Mergers and Acquisitions in India: Some Issues, AIMA Journal of Management and Research, 1(2).

10. Schuler, R. S., \& Jackson, S.E. (2001). HR Issues and Activities in Mergers and Acquisitions, European Management Journal, 19(3), 239-253.

11. Scott (2003). Wall Street Words: An A to Z Guide to Investment Terms for Today's Investor.

12. Sherman and Hart, (2006). Mergers and Acquisitions from A-Z. Amacom.

13. Veeraselvam, M., (2014). Impact of Mergers and Acquisition in Corporate Sector: Issues in Human Resource Management, Shanlax International Journal of Commerce, 2(3), 65-71. 